\title{
Acessibilidade do Parque Natural Municipal Victório Siquierolli (Uberlândia/MG) para visitação de pessoas com deficiências física, auditiva e visual
}

\author{
Accessibility of Parque Natural Municipal Victório Siquierolli (Uberlândia / MG) for visits of people with physical, \\ hearing and visual disabilities \\ Accesibilidad del Parque Natural Municipal Victorio Siquierolli (Uberlandia / MG) para la visitación de personas \\ con discapacidad física, auditiva y visual
}

Ana Beatriz Leça de Lima

Universidade Federal de São Carlos (UFScar), Brasil

bia_leca@hotmail.com

DOI: https://doi.org/10.18472/cvt.19n3.2019.1574 Redalyc: http://www.redalyc.org/articulo.oa? id $=115461709008$

\author{
Ismail Barra Nova de Melo \\ Universidade Federal de São Carlos (UFScar), Brasil \\ ismail.barra@gmail.com
}

Maria Henriqueta Sperandio Garcia Gimenes-Minasse

Universidade Anhembi Morumbi (UAM), Brasil

mariegimenes@gmail.com

Recepción: 31 Enero 2018

Aprobación: 27 Septiembre 2019

\section{Resumo:}

A acessibilidade de pessoas com deficiência em parques ainda é pouco abordada e, quando trabalhada, as deficiências são tratadas de forma isolada, sendo que os espaços e serviços públicos deveriam prever todas as demais categorias de deficiência simultaneamente. Decorrente disso, esse trabalho tem como objetivo principal analisar a acessibilidade para três tipos de deficiência: física, auditiva e visual nas dependências e atividades oferecidas pelo Parque Natural Municipal Victório Siquierolli, localizado em Uberlândia/ MG. A metodologia foi dividida em pesquisa bibliográfica e documental e pesquisa de campo. A pesquisa de campo incluiu a observação direta utilizando como instrumento de coleta um protocolo elaborado a partir da Norma Brasileira (NBR) 9050/2015. Com os resultados obtidos, percebe-se que o parque não apresenta todas as estruturas para acessibilidade que a norma NBR 9050 exige e as estruturas existentes não estão totalmente adequadas, tendo em vista auxiliarem apenas as pessoas com deficiência física, especificadamente os cadeirantes. Logo, se fazem necessárias adaptações que possam beneficiar as demais categorias de deficiência abordadas nesse estudo, de forma a melhorar a estrutura do parque e consequentemente aumentar e diversificar a visitação.

Palavras-chave: Acessibilidade, Deficiência auditiva, Deficiência física, Deficiência visual, Unidade de Conservação.

\begin{abstract}
:
The accessibility for park users with disabilities is rarely addressed. When it is addressed, the types of disabilities are treated individually. However, it is noteworthy that public spaces and services are used by all categories simultaneously. Due to that fact, the main purpose of this work is to analyze the accessibility for three types of disabilities: physical, hearing and visual. This was done in the facilities and activities offered by the Parque Natural Municipal Victório Siquierolli, located in Uberlândia / Minas Gerais. The research methodology was divided into literature review and documentary research and field research. Field research included direct observation using as a gathering instrument, a protocol based on Brazilian Standard NBR 9050/2015. With the results, we can notice that the park does not have all the structures for accessibility that Brazilian Standard (NBR) 9050/2015 standard requires, and the present structures, such as ramps, signs, handicap restrooms and free space for movement are not entirely suitable, with a view only to assist people with physical disabilities, more specifically wheelchair users. So necessary adjustments should be done to benefit other disability categories cited in this study, in order to improve the structure of the park and as a consequence increase and diversify the visits.
\end{abstract}

KEYwords: Acessibilidade, Deficiência auditiva, Deficiência física, Deficiência visual, Unidade de Conservação.

\section{Resumen:}

La accesibilidad de personas con discapacidad en parques todavía es poco abordada y, cuando se trabaja, las deficiencias son tratadas de forma aislada, siendo que los espacios y servicios públicos son utilizados por todas las demás categorías de 
discapacidad simultáneamente. En consecuencia, este trabajo tiene como objetivo principal analizar la accesibilidad para tres tipos de discapacidad: física, auditiva y visual en las dependencias y actividades ofrecidas por el Parque Natural Municipal Victorio Siquierolli, ubicado en Uberlândia / MG. La metodología fue dividida en investigación bibliográfica y documental e investigación de campo. La investigación de campo incluyó la observación directa utilizando como instrumento de recolección un protocolo elaborado a partir del Estándar brasileño NBR 9050/2015. Con los resultados obtenidos, se percibe que el parque no presenta todas las estructuras para accesibilidad que la norma NBR 9050 exige y las estructuras existentes no son totalmente adecuadas, con el fin de ayudar a las personas con discapacidad física, más específicamente a los asientos. Por lo tanto, se hacen necesarias adaptaciones que puedan beneficiar a las demás categorías de discapacidad abordadas en ese estudio, para mejorar la estructura del parque y consecuentemente aumentar y diversificar lass visitas.

Palabras Clave: Acessibilidad, Pérdida de audición, Deficiencia física, Deficiencia visual, Unidad de Conservación.

\section{INTRODUÇÃO}

A Constituição Federal do Brasil de 1988 garante a participação de todas as pessoas com deficiência nos espaços e serviços públicos de uso coletivo, como espaços de recreação, lazer, cultura, educação, entre outros (BRASIL, 1988). Segundo a Política Nacional para a Integração da Pessoa Portadora de Deficiência as deficiências podem ser categorizadas em: física (comprometimento da função física devido à alteração de um ou mais segmentos do corpo humano), visual (cegueira e baixa visão), auditiva (perda de 41 decibéis ou mais), mental (funcionamento intelectual significativamente inferior à média com limitações associadas a duas ou mais áreas de habilidades adaptativas, manifestadas antes dos dezoito anos) e múltipla (duas ou mais deficiências) (BRASIL, 1999).

Dados do Instituto Brasileiro de Geografia e Estatística (IBGE) indicam que 23,9\% da população brasileira apresenta pelo menos um tipo de deficiência, sendo 18,8\% com deficiência visual, $7 \%$ com deficiência física, $5,1 \%$ com deficiência auditiva e 1,4\% com deficiência mental (IBGE, 2012). Desta forma, é imprescindível que se promova a acessibilidade nos espaços e serviços públicos de uso coletivo. As Leis n ${ }^{\circ} 10.098$, de 19 de dezembro de 2000 e no 13.146 de 6 de julho de 2015 definem que a acessibilidade consiste em proporcionar condições de utilização de espaços e serviços de uso coletivo de forma segura e autônoma para pessoas com deficiência (BRASIL, 2000a, 2015). As Unidades de Conservação (UCs), em especial os Parques Nacionais, Estaduais e Municipais são exemplos de locais de uso público coletivo que podem oferecem atividades de turismo, lazer e educação ambiental para a população em geral (BRASIL, 2000b). (Error 6: La referencia debe estar ligada) (Error 7: El tipo de referencia es un elemento obligatorio) (Error 8: No existe una URL relacionada) (Error 9: La referencia debe estar ligada) (Error 10: El tipo de referencia es un elemento obligatorio) (Error 11: No existe una URL relacionada) (Error 12: La referencia debe estar ligada) (Error 13: El tipo de referencia es un elemento obligatorio) (Error 14: No existe una URL relacionada)

Contudo, o tema acessibilidade para pessoas com deficiência em parques ainda é pouco abordado, tanto academicamente quanto no planejamento e na gestão destas áreas, seja do ponto de vista da gestão urbana ou do turismo. E, muitas vezes, as diferentes deficiências são abordadas de forma isolada, apesar do uso simultâneo destes espaços por pessoas com diferentes características e necessidades. A inclusão parcial, além de restritiva, pode causar constrangimento a grupos específicos, fazendo com que a funções de integração, de convívio e de lazer que deveriam ser proporcionadas não sejam cumpridas.

No município de Uberlândia, Minas Gerais, encontra-se o Parque Natural Municipal Victório Siquierolli (a partir de agora denominado PNMVS), que tem papel relevante na educação ambiental regional por abrigar o Museu de Biodiversidade do Cerrado (MBC), desenvolver atividades com escolas do município e a sociedade em geral e apoiar atividades de pesquisa e de extensão da Universidade Federal de Uberlândia (UFU) (UBERLÂNDIA, 2015). O Parque é um dos oito parques naturais do município, compondo a oferta turística e de lazer local.

Levando em consideração a escassez de trabalhos relacionados à acessibilidade em parques no contexto do lazer e do turismo e a necessidade de trabalhar ações de inclusão que envolvam diferentes tipos de deficiências, 
além da relevância do Parque, esta pesquisa teve como objetivo analisar se o PNMVS apresenta infraestrutura e atividades adequadas, segundo os parâmetros estabelecidos pela Associação Brasileira de Normas Técnicas [1] (ABNT) por meio da Norma Brasileira (NBR) 9050/2015 (que trata daa acessibilidade em edificações, mobiliário, espaços e equipamentos urbanos), para o acesso de pessoas com deficiências física, auditiva e visual.

\section{REFERENCIAL TEÓRICO}

Para a efetiva inclusão de todas as categorias de deficiências e ainda das demais pessoas, os espaços e serviços de uso público precisam ser adaptados. De acordo com a Lei $\mathrm{n}^{\circ} 10.098$, de 19 de dezembro de 2000, que estabelece normas gerais e critérios básicos para a promoção da acessibilidade de pessoas portadoras de deficiência ou com mobilidade reduzida, acessibilidade é:

Possibilidade e condição de alcance para utilização, com segurança e autonomia, de espaços, mobiliários, equipamentos urbanos, edificações, transportes, informação e comunicação, inclusive seus sistemas e tecnologias, bem como de outros serviços e instalações abertos ao público, de uso público ou privados de uso coletivo, tanto na zona urbana como na rural, por pessoa com deficiência ou com mobilidade reduzida (BRASIL, 2000, s/p).

A acessibilidade deve ocorrer tanto na parte estrutural e física dos espaços e mobiliários quanto nas formas de informação e comunicação disponibilizadas aos usuários. Segundo Sassaki ([s/d], apud BORGES, 2014, p.91), a acessibilidade se desdobra em diferentes frentes, todas elas necessárias para garantir o livre acesso de qualquer cidadão a espaços e serviços públicos. São elas: acessibilidade arquitetônica[2], acessibilidade atitudinal[3], acessibilidade comunicacional[4], acessibilidade instrumental[5], acessibilidade metodológica[6], acessibilidade programática[7]. Essas abordagens devem ser planejadas e executadas de forma a incluir a maior quantidade de pessoas possível, independente de idade, estatura, limitação de mobilidade ou de percepção (ABNT, 2004). (Error 1: La referencia debe estar ligada) (Error 2: El tipo de referencia es un elemento obligatorio) (Error 3: No existe una URL relacionada)

O impedimento para realizar atividades, como andar, permanecer em um local, utilizar um objeto, entre outros, não decorre das pessoas, mas sim do ambiente onde se está, daí a importância de adaptar e tornar acessível os espaços e instrumentos de uso público (ANSELMO; VOLTOLIN, 2010). Para tal, existe o desenho universal que é a otimização dos espaços, artefatos e produtos de forma a atender o maior número de pessoas simultaneamente, com diferentes características antropométricas e sensoriais, de forma autônoma, segura e confortável (BRASIL, 2004; CASSAPIAN; RECHIA, 2014, ABNT, 2015).

A Norma Brasileira da ABNT: 9050, na atual versão, tem como objetivo estabelecer critérios e parâmetros técnicos de acessibilidade a serem observados em projetos, construções, instalações e adaptações de edificações, mobiliários, espaços e equipamentos no meio urbano e rural (ABNT, 2015). Esta Norma institui, assim, para estes espaços e objetos, parâmetros de desenho universal para atender portadores de diferentes tipos de deficiência.

No contexto do turismo brasileiro, a principal referência sobre acessibilidade é a publicação, pela Embratur, do 'Manual de recepção e acessibilidade de pessoas com deficiência a empreendimentos e equipamentos turísticos', em 2001. Em 2006, o Ministério do Turismo publicou uma versão revisada e ampliada, intitulada 'Manual de orientações: turismo e acessibilidade'. No documento mais recente, são apresentados termos e definições pertinentes, é realizada uma contextualização do conjunto normativo que rege o tema e são explanadas orientações específicas sobre o atendimento e a adequação de espaços e edificações, de meios de transporte e de comunicações e informações para garantir a acessibilidade de todos.

Do ponto de vista acadêmico, identificou-se algumas pesquisas que tratam da questão da acessibilidade associada ao turismo, algumas voltadas para serviços e equipamentos turísticos, outras para atrativos ou destinos turísticos propriamente ditos.

Em relação aos serviços turísticos, tratando da acessibilidade no contexto da hotelaria, Franzen e Reis (2013) estudaram a realidade dos empreendimentos de Santa Maria (RS) e Duarte e Borda (2013) o parque hoteleiro de Brasília (DF).Bizinelli et al. (2014) estudaram a acessibilidade de uma vinícola premiada no interior do Paraná tendo como parâmetros as necessidades dos deficientes visuais. Da Silva e Leal (2011) analisaram a adaptação da infraestrutura física e do atendimento de três restaurantes da cidade de Natal para garantir a acessibilidade de usuários portadores de diferentes deficiências.

Sobre as abordagens relacionadas aos atrativos e destinos turísticos, menciona-se o trabalho de Mello et al. (2010), que avaliaram a acessibilidade de alguns espaços de lazer da cidade de Natal (RN), incluindo praias, parques e cinema. A pesquisa de Pereira (2011) analisou a acessibilidade dos portadores de necessidades físicas e visuais em equipamentos turísticos do município de Belém (PA).Duarte e Souza (2013) averiguaram a acessibilidade para deficientes visuais no Corredor Cultural de Mossoró em diversos aspectos. 
De forma específica, tratando da acessibilidade de parques no contexto turístico, têm-se as pesquisas de Silva et al. (2013) que investigaram o nível de acessibilidade de um parque público de Campo Grande (MS); e a de Carvalho (2012) que analisou a adaptação da infraestrutura do Parque Nacional da Serra da Capivara (PI) para garantir a acessibilidade para deficientes e pessoas de mobilidade reduzida. Abordando a inclusão de pessoas com deficiência em parques em um contexto não turístico destacam-se os trabalhos de Silva (2011) sobre a acessibilidade de deficientes físicos nos Parques do Sabiá e no PNMVS em Uberlândia (MG); de Moriwaki (2011) sobre acessibilidade de deficientes visuais no Parque Estadual do Jaraguá, no município de São Paulo; de Borges (2014) sobre a acessibilidade de deficientes visuais em parques urbanos e o de Queiroz (2014) sobre a acessibilidade no contexto da educação ambiental.

\section{PROCEDIMENTOS METODOLÓGICOS}

Uberlândia é um município integrante do Triângulo Mineiro cujo povoamento se iniciou no século XIX. Atualmente, possui cerca de 646.673 habitantes e tem como principais setores da economia a pecuária e a indústria (IBGE, 2017). Do ponto de vista turístico, possui a segunda maior rede hoteleira de Minas Gerais e é um destino de negócios (por conta de seu parque industrial diversificado) e de turismo religioso (por conta do túmulo e do Museu de Chico Xavier), e integra o Circuito Turístico dos Lagos e o Circuito Turístico do Triângulo (OBSERVATÓRIO DO TURISMO DE MINAS GERAIS, 2017).

O município possui oito parques ${ }^{[8]}$ que representam menos de $2 \%$ da área urbana total (MOREIRA et al., 2011), dentre eles o PNMVS. O Parque foi criado pelo Decreto $\mathrm{n}^{\circ} 8.166$ de 5 de maio de 2000 e inaugurado em 31 de agosto de 2002. De acordo com este Decreto e com a Lei no 9985 de 18 de julho de 2000, que instituiu o Sistema Nacional de Unidades de Conservação da Natureza, o Parque se enquadra nas categorias de Proteção Integral e de Parque Natural Municipal.

O parque se encontra no setor norte da cidade, abrange uma área de $237.152,75 \mathrm{~m}^{2}$, sendo uma parte desta área pública derivada de loteamentos aprovados pela Prefeitura Municipal e outra parte privada doada pelo proprietário da fazenda, o Sr. Victório Siquierolli. Atualmente o PNMVS é administrado pela Secretaria Municipal do Meio Ambiente. O horário de funcionamento é de terça-feira à domingo, de $08 \mathrm{~h}$ às $17 \mathrm{~h} 30$. (UBERLÂNDIA, 2015).

A visitação no PNMVS acontece de duas formas: livre/autoguiada para o público em geral ou mediante agendamento para instituições (escolas, faculdades, universidade, grupos religiosos) com acompanhamento dos monitores e educadores ambientais. Dados disponibilizados indicam que entre os anos de 2007 e 2015 foram atendidos em torno de 185 instituições por ano, totalizando 12.366 acadêmicos, além dos visitantes livres. O quadro 1 apresenta as estruturas e atrações que integram o PNMVS: 
QUADRO 1

Estruturas e atrações que integram o PNMVS

\begin{tabular}{|c|c|c|}
\hline & Estrutura & Breve descritivo \\
\hline 1 & $\begin{array}{l}\text { Museu da } \\
\text { Biodiversidade } \\
\text { do Cerrado } \\
\text { (MBC) }\end{array}$ & $\begin{array}{l}\text { É uma unidade especial do Instituto de Biologia da } \\
\text { UFU (Universidade Federal de Uberlândia), } \\
\text { composto por um acervo com cerca de } 266 \\
\text { espécies taxidermizadas de fauna e herborizada de } \\
\text { flora do bioma Cerrado, coleçóes de insetos e } \\
\text { sementes, todos identificados com dados e } \\
\text { curiosidades sobre cada espécie exposta. Além } \\
\text { desses atrativos, o museu possui cartazes com } \\
\text { informaçôes do bioma Cerrado, } 47 \text { ninhos de aves } \\
\text { e insetos e } 10 \text { esqueletos (COIMBRA, 2005; SILVA, } \\
\text { 2010; MOREIRA et al., 2011; UNIVERSIDADE } \\
\text { FEDERAL DE UBERLANDIA, 2015a). }\end{array}$ \\
\hline 2 & $\begin{array}{l}\text { Sala Verde } \\
\text { Dr. Kerr }\end{array}$ & $\begin{array}{l}\text { É um espaço destinado para leituras, pesquisas e } \\
\text { videos, composto pela "Biblioteca Verde" com } \\
\text { materiais fornecidos pelo Ministério do Meio } \\
\text { Ambiente (MMA) (COIMBRA, 2005; COIMBRA; } \\
\text { CUNHA, 2005). }\end{array}$ \\
\hline 3 & $\begin{array}{l}\text { Cantinho das } \\
\text { Abelhas }\end{array}$ & $\begin{array}{l}\text { Criado recentemente pelo MBC, é um meliponário } \\
\text { onde se cria abelhas sem ferräo em cinco colônias } \\
\text { divididas e ocupadas por duas espécies, Jatai e } \\
\text { Mandaçaia (UNIVERSIDADE FEDERAL DE } \\
\text { UBERLANDIA, 2015b). }\end{array}$ \\
\hline 4 & Trilha do Óleo & $\begin{array}{l}\text { É usada tanto para visitas agendadas como para os } \\
\text { visitantes livres, percorre aproximadamente } 300 \text { m } \\
\text { em uma região de Mata de Galeria, e composta por } \\
\text { placas com informaçóes sobre a vegetaçâo } \\
\text { (COIMBRA, 2005; COIMBRA; CUNHA, 2005; } \\
\text { UBERLANDIA, 2015). A trilha recebe esse nome por } \\
\text { possuir um exemplar de Copaifera langsdorffii, } \\
\text { popularmente conhecida como copaiba, pau-de- } \\
\text { óleo e óleo-de-copaiba devido ao óleo que extraido } \\
\text { do seu caule com propriedades de cicatrização e } \\
\text { anti-inflamatório (CoIMBRA, 2005). }\end{array}$ \\
\hline 5 & $\begin{array}{l}\text { Pista de } \\
\text { caminhada }\end{array}$ & $\begin{array}{l}\text { Pouco utilizada devido à sua estrutura precária e à } \\
\text { falta de iluminação e segurança no decorrer do } \\
\text { caminho. }\end{array}$ \\
\hline 6 & $\begin{array}{l}\text { Parque } \\
\text { infantil }\end{array}$ & $\begin{array}{l}\text { É todo feito de madeira e cordas, localizado } \\
\text { próximo ao MBC e encontra-se em bom estado de } \\
\text { conservação. Nele são encontrados balanços, } \\
\text { escorregadores e gangorras, e é muito utilizado } \\
\text { pelas crianças que fazem a visita agendada, sendo } \\
\text { que em muitas escolas não possuem tal estrutura } \\
\text { para lazer. }\end{array}$ \\
\hline
\end{tabular}

os autores (2018)

O Parque possui ainda uma rede de drenagem composta pelo Córrego Liso e o Córrego do Carvão que abastecem a bacia do Rio Uberabinha. É importante observar que, como pontua Coimbra (2005), não há muitas praças e áreas de entretenimento para a população do entorno, o que potencializa o uso recreativo do PNMVS.

Destaca-se ainda que o Parque funciona como uma unidade de pesquisa e extensão para a Universidade Federal de Uberlândia (UFU), desenvolvendo atividades relacionadas à Educação Ambiental (EA) com alunos e professores daquela Instituição, além da sociedade em geral. Estas funções - de espaço público de lazer, de pesquisa e de educação ambiental - reforçam a necessidade de que o PNMVS esteja adaptado de forma a receber seus visitantes de forma democrática, atendendo diferentes públicos com suas respectivas necessidades. E além de atender à população local, estas adaptações podem permitir o acesso aos visitantes 
com deficiência, representando uma importante contribuição para a oferta turística adaptada da cidade, que não é muito expressiva.

Considerando o objetivo deste trabalho, a pesquisa foi desenvolvida em duas etapas: a primeira constituída por pesquisa bibliográfica e documental e a segunda pela pesquisa de campo. A pesquisa bibliográfica analisou estudos sobre a inclusão de pessoas com deficiência em parques e no contexto do lazer e do turismo. A pesquisa documental considerou as legislaçóes das esferas federal, estadual e municipal relacionadas às iniciativas de proteção e garantia de acessibilidade às pessoas com deficiência; além de outros documentos pertinentes.

A pesquisa de campo analisou a infraestrutura e as atividades do Parque a partir de observações estruturadas (sistemáticas), não participante e com registros fotográficos das estruturas físicas e das atividades oferecidas aos visitantes, com autorização concedida pela gerência local. Registrou-se se existe ou não acessibilidade para deficientes físicos, auditivos e visuais, se os espaços de circulação e de acesso são adequados de acordo com a ABNT NBR 9050, e se as atividades oferecidas (jogos interativos) são acessíveis a todas as categorias de deficiência. O instrumento de coleta de dados foi elaborado a partir da ABNT NBR 9050 de 2015 e de trabalhos que avaliaram objetos semelhantes por meio dessa Norma. O quadro 1 apresenta a síntese do protocolo de análise: 
QUADRO 2

Itens que compõem o protocolo de análise do PNMVS

\begin{tabular}{|c|c|c|c|}
\hline Item & Descritivo & $\begin{array}{l}\text { A spectos } \\
\text { avaliados }\end{array}$ & \begin{tabular}{|l} 
Deficiências \\
contempladas \\
nesta análise
\end{tabular} \\
\hline 1 & $\begin{array}{l}\text { Checklist dos } \\
\text { Parâmetros } \\
\text { antropométricos e suas } \\
\text { respectivas medidas }\end{array}$ & $\begin{array}{l}\text { - Dimensões } \\
\text { referenciais } \\
\text { para } \\
\text { deslocamento } \\
\text { de pessoas } \\
\text { em pé - } \\
\text { Dimensões } \\
\text { referenciais } \\
\text { para } \\
\text { deslocamento } \\
\text { de pessoas } \\
\text { em cadeira } \\
\text { de rodas - } \\
\text { Área de } \\
\text { circulação }\end{array}$ & Física e Visual \\
\hline 2 & $\begin{array}{l}\text { Checklist das } \\
\text { características de } \\
\text { Informação e } \\
\text { Sinalização }\end{array}$ & $\begin{array}{l}\text { - Categorias } \\
\text { de } \\
\text { sinalização - } \\
\text { Tipos de } \\
\text { sinalização - } \\
\text { Disposição } \\
\text { das } \\
\text { sinalizações } \\
\text { - Linguagem } \\
\text { - Símbolos - } \\
\text { Aplicações } \\
\text { essenciais }\end{array}$ & $\begin{array}{l}\text { Física, Visual e } \\
\text { Auditiva }\end{array}$ \\
\hline 3 & $\begin{array}{l}\text { Checklist das } \\
\text { características de Acesso } \\
\text { e Circulação }\end{array}$ & $\begin{array}{l}\text { - Acessos - } \\
\text { Rampas - } \\
\text { Degraus e } \\
\text { escadas fixas } \\
\text { - Corrimãos } \\
\text { - Circulação } \\
\text { inteira - } \\
\text { Circulação } \\
\text { externa - } \\
\text { Vagas para } \\
\text { veículos }\end{array}$ & Física e Visual \\
\hline 4 & $\begin{array}{l}\text { Checklist das } \\
\text { Características dos } \\
\text { sanitários }\end{array}$ & $\begin{array}{l}\text { - Localização } \\
\text { e sinalização } \\
\text { - Acessórios } \\
\text { para } \\
\text { sanitários }\end{array}$ & $\begin{array}{l}\text { Física, Visual e } \\
\text { Auditiva }\end{array}$ \\
\hline 5 & $\begin{array}{l}\text { Checklist de Mobiliários } \\
\text { Urbanos }\end{array}$ & $\begin{array}{l}\text { - Parques, } \\
\text { praças e } \\
\text { locais } \\
\text { turísticos - } \\
\text { Bibliotecas e } \\
\text { centros de } \\
\text { leitura }\end{array}$ & $\begin{array}{l}\text { Física, Visual e } \\
\text { Auditiva }\end{array}$ \\
\hline 6 & Checklist de Mobiliários & $\begin{array}{l}\text { - Bebedouros } \\
\text { - Vegetação }\end{array}$ & $\begin{array}{l}\text { Física, Visual e } \\
\text { Auditiva }\end{array}$ \\
\hline 7 & $\begin{array}{l}\text { Checklist de } \\
\text { Equipamentos Urbanos }\end{array}$ & - Mesa & Física, Visual \\
\hline
\end{tabular}

os autores (2018) baseando-se em ABNT NBR 9050 (2015) 
Foi considerada a presença (ou ausência) dos aspectos avaliados eforam aferidas as medidas relacionadas, para posterior comparação com a Norma vigente. Os resultados são apresentados de forma sintetizada no próximo item.

\section{APRESENTAÇÃO E DISCUSSÃO DOS RESULTADOS}

A apresentação dos resultados segue a ordem dos itens descritos no protocolo utilizado: parâmetros antropométricos; informação e sinalização; acessos e circulação; sanitários; mobiliários urbanos; mobiliários; equipamentos urbanos.

a) Parâmetros antropométricos: esta análise começou na entrada do Parque e seguiu até o seu interior. Os locais e a sequência escolhida dessa análise foram: A - Entrada, B - Caminho para pedestres, C - Trilha do Óleo, D - Cantinho da Abelha, E - Pista de Caminhada, F - Parque Infantil, G - Museu de Biodiversidade. A Figura 1 mostra essa sequência por meio de uma imagem de satélite do PNMVS.

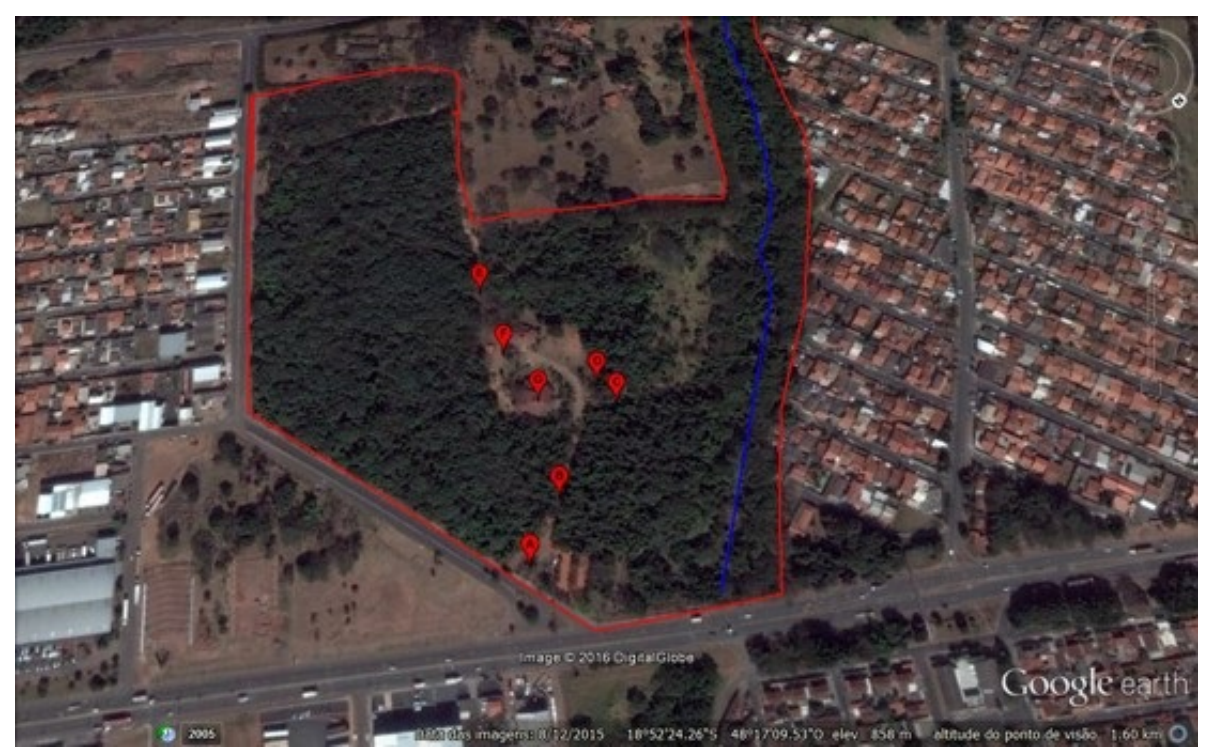

FIGURA 1

Imagem satélite do PNMVS e a sequência das estruturas analisadas no item: Parâmetros Antropométricos Google Earth (2016)

No ponto A (entrada do Parque) observou-se uma entrada para pedestres, que estava fechada, e duas entradas para veículos, sendo que na ocasião somente uma estava aberta. Nenhuma delas possui sinalização para qualquer deficiência. Foram aferidas as medidas apenas da entrada de veículos aberta. Tal entrada possui uma largura superior a 2,0 m, que é a referência máxima das dimensões da Norma, mas não possui um asfaltamento regular e os pedestres deveriam compartilhá-la com veículos.

O ponto A se desdobra em dois caminhos, um caminho para pedestres (ponto B) e um para veículos. Somente o ponto B foi analisado: ele segue até a entrada do Museu de Biodiversidade do Cerrado (ponto $\mathrm{G})$. Este caminho apresenta boas condições, piso regular e estável e uma largura de 2,0 $\mathrm{m}$, contemplando as medidas exigidas nos Parâmetros Antropométricos tanto para o deslocamento de pessoas em pé e de pessoas com cadeira de rodas quanto para a área de circulação. Porém, não possui nenhuma marcação visual, tátil ou sonora para o auxílio das pessoas com deficiência visual e auditiva.

O ponto C (Trilha do Óleo) não apresenta acessibilidade para nenhuma pessoa com qualquer tipo e grau de deficiência de mobilidade física e visual. $\mathrm{O}$ caminho que direciona para o início da trilha possui apenas 0,70 $\mathrm{m}$ de largura, é formado por bloquetes que criam uma superfície instável e desnivelada e em vários trechos a vegetação invade o espaço de deslocamento (incluindo raízes e troncos), não havendo qualquer aviso (visual 
ou tátil) alertando sobre estas características. A entrada da Trilha do Óleo tem um início confuso, já que existem dois caminhos possíveis de serem percorridos e apenas uma placa interativa dando início ao jogo ${ }^{[9]}$ que existe ao longo da trilha. O caminho é de terra batida com alguns desníveis e repleto de galhos, folhas e raízes de plantas, não atendendo os padrões exigidos pela Norma. A sinalização é feita somente pelas placas do jogo interativo, sem que haja tradução para o Braile ${ }^{[10]}$, e por troncos de árvores cortados que ficam dispostos no chão e indicam o caminho a ser percorrido.

O ponto D (Cantinho da Abelha) possui dois locais de entretenimento: os meliponários ${ }^{[11]}$ e um espaço para piquenique com uma mesa comunitária. Para chegar nesses dois espaços é preciso passar por um degrau coberto pela vegetação, o que impede totalmente o acesso de cadeirantes e pessoas com baixa visão/cegueira. $\mathrm{O}$ caminho até o local reservado para piquenique é feito por uma passarela de madeira e que apresenta $1,0 \mathrm{~m}$ de largura, dimensão que não corresponde aos padrões exigidos já descritos. $\mathrm{O}$ caminho para os meliponários possui duas rampas em madeira e o restante é composto por grama, o que dificulta o acesso de pessoas com dificuldade de locomoção e deficiência visual.

O ponto D (Pista de caminhada), localizado na extremidade do Parque, possui um caminho inicial possui uma largura de 1,45 m de terra batida e está parcialmente estável. Esta primeira porção possibilita o uso por pessoas a pé, com ou sem auxílio de objetos, e por pessoas em cadeira de rodas, inclusive com a realização de manobras sem obstáculos. Em poucos metros, contudo, o espaço é reduzido para 0,95 m de largura, dificultando o deslocamento das pessoas em cadeira de rodas.

O ponto $\mathrm{F}$ (Parque infantil) é todo de grama, com a superfície irregular, o que dificulta o acesso para deficientes físicos e visuais. O último ponto de análise foi o Museu de Biodiversidade do Cerrado (ponto G). $\mathrm{O} \mathrm{MBC}$ possui piso de cerâmica, estável e regular, e um amplo espaço livre de circulação, o que permite o deslocamento por todas as categorias e dimensões referentes aos Parâmetros Antropométricos.

Analisando a estrutura observada no PNMVS a partir das exigências da ABNT NBR 9050, apenas a entrada de veículos, o caminho para pedestres e o MBC estão adaptados para pessoas com deficiência física. Os mesmos locais adaptados para a deficiência física são adaptados para as pessoas com deficiência visual que utilizam o cão-guia, mas não há piso tátil em nenhum local do Parque. A deficiência auditiva não se enquadra nessa análise, por não comprometer a locomoção.

Comparando os resultados encontrados com o de outras pesquisas, algumas similaridades são observadas. Carvalho (2012), ao analisar a acessibilidade dos sítios arqueológicos do Parque Nacional da Serra da Capivara, constatou que apesar de algumas áreas estarem adaptadas, possuem medições inferiores ao que é recomendado, o que dificulta o deslocamento adequado (incluindo a realização de manobras) para cadeirantes. A análise de Melo e Orlando (2014) indicou que os maiores problemas de acessibilidade do Parque Natural Municipal Victório Siquierolli são: o chão de bloquetes, que dá acesso a maioria dos atrativos do local, e o gramado no Parque Infantil (dois aspectos também observados nesta análise).

Por outro lado, o trabalho de Moriwaki (2011), que analisou a acessibilidade para pessoas com deficiência visual no Parque Estadual do Jaraguá, mostrou que é possível adaptar as trilhas para o acesso de cadeirantes e pessoas com dificuldade de visão: há neste parque uma trilha com as dimensões recomendadas pela Norma e com toda a sua extensão nivelada por madeiramento ou terra batida, acompanhada de corrimãos e guias de balizamento. Isto evidencia que, mesmo que áreas naturais não possam sofrer muitas alterações na sua estrutura original, é possível adaptar os principais locais de acesso dos visitantes e as principais atividades oferecidas, de acordo com os objetivos de cada UC.

b) Informação e sinalização: as análises consideraram todas as estruturas de informação e sinalização do Parque, sem separação por locais, como feito na subseção anterior. Foram encontradas placas informativas e direcionais, ou seja, indicando o nome dos locais e a direção dos mesmos, apontados a partir de setas. Nenhuma das placas continha informações em Braille.

As placas localizadas na área externa do PNMVS são todas feitas em madeira e indicam: na entrada do Parque, o estacionamento geral e o estacionamento para pessoas com deficiência; no caminho para pedestres, 
o acesso ao MBC e a sede da Secretaria Municipal do Meio Ambiente; o acesso para a Trilha do Óleo; no estacionamento para pessoas com deficiência, o caminho acessível para o MBC. A baixa altura destas placas é muitas vezes um empecilho, tendo em vista que a vegetação dificulta a visibilidade do conteúdo, que também é apresentado de forma pouco legível (o tamanho e a cor das fontes não seguiam a regra do contraste). A Norma ABNT NBR 9050 exige que as sinalizações estejam localizadas de forma a identificar claramente o ambiente, em uma altura que favoreça a legibilidade e que possam ser compreendidas por todos.

Dentro do $\mathrm{MBC}$ foi encontrada uma placa sinalizando os sanitários. Esta placa está a uma altura de 1,60 m do chão, sem identificação em Braille ou alto relevo. As demais placas encontradas eram referentes às atividades interativas que o Parque oferece, como a do jogo interativo na Trilha do Óleo. Mas não são compatíveis com a ABNT NBR 9050, que determina que as informações deveriam estar em fonte maior e acompanhadas do Sistema Braille ou alto relevo. O Museu possui vitrines de vidro que expóem a fauna e a flora do Bioma Cerrado e junto aos exemplares estão as placas com informações relevantes sobre aquela espécie. O vidro atrapalha a legibilidade dos textos, por conta do reflexo. Além disso, o tamanho da fonte utilizada nessas placas é muito pequeno e de difícil leitura.

A ABNT NBR 9050/2015 recomenda que as palavras sejam escritas com a combinação de letras maiúsculas e minúsculas e sem fontes itálicas, sem decoração e sem sombras ou aparência tridimensional. As sinalizações precisam seguir o contraste escuro-claro ou claro-escuro, ou seja, se o fundo for escuro o conteúdo deve ser claro e vice-versa. A Norma ainda estabelece que devem ser evitados materiais brilhantes ou de alta reflexão.

A ABNT NBR 9050/2015 também se refere a símbolos. Dos diversos símbolos representados na Norma, o único presente no Parque foi o Símbolo Internacional de Acesso. Porém, esse símbolo possui características específicas de cor e desenho, e os locais onde esse símbolo foi encontrado (a placa de sinalização do estacionamento e a placa de acesso ao MBC) obedecem apenas parcialmente a regra das cores.

Com relação às aplicações essenciais, somente as sinalizações de degraus e de vagas para deficientes físicos foram analisadas, devido à ausência das demais estruturas mencionadas nesse tópico na ABNT NBR 9050/2015. A única escada fixa presente no PNMVS dá acesso ao MBC e não apresenta nenhuma sinalização visual e tátil nos degraus e no corrimão.

Sobre a sinalização de vagas reservadas para veículo de pessoas com deficiência, a Norma ABNT NBR 9050/2015 recomenda que essas sejam aplicadas na vertical, contendo o Símbolo Internacional de Acesso e instaladas a uma altura livre de 2,10 m e 2,50 m em relação ao solo. O PNMVS possui duas vagas reservadas, sendo uma vaga para deficiência física e a outra vaga para idoso. A placa de sinalização da vaga reservada para deficiente físico está na altura recomendada, com símbolo de acesso dentro dos padrões. Porém, o fato do chão ser de grama e apresentar instabilidade e desnivelamento dificulta o desembarque desse grupo de visitantes.

O item informação/sinalização deveria contemplar todas as três deficiências: física, visual e auditiva. As informações visuais existentes atendem aos deficientes físicos e auditivos, mas as barreiras para os deficientes visuais são várias: não há textos em alto relevo e em Braille, não há piso tátil ou um mapa acessível na entrada.

Queiroz (2014), ao analisar a acessibilidade para pessoas com deficiência visual em parques urbanos, mostrou por meio de entrevistas realizadas com especialistas que é fundamental que um deficiente visual tenha o mínimo de informação antes de percorrer um parque sozinho. Essa informação pode ser disponibilizada com uma descrição geral ou um mapa tátil. Ao entrevistar deficientes visuais, constatou-se a importância de informações em Braille, do uso de letras ampliadas por todo o Parque, de audioguias e da presença do piso tátil direcionando até os principais atrativos.

O estudo de Moriwaki (2011) enfatizou o uso das placas em Braille para esse público, discutindo também a importância da disposição dessas placas, uma vez que elas geralmente são feitas de material metálico e na maioria das vezes ficam expostas ao sol, dificultando o toque para leitura. Em espaços abertos, como no PNMVS, o ideal é que o material utilizado seja a madeira. 
Observou-se que a exposição da fauna e da flora no MBC também não favorece o público com dificuldades de visão. Moriwaki (2011) e Line e Mergulhão (2014) sugerem alguns recursos alternativos que poderiam ser adotados no PNMVS, por exemplo: criar um sistema de áudio com a descrição dos exemplares, acrescentar figuras em alto relevo ou até mesmo expor as peças de forma que os visitantes, com auxílio de um mediador, possam tocá-las.

c) Acessos e circulação: muitos dos aspectos avaliados aqui em sua maioria já foram avaliados nos Parâmetros Antropométricos. O Parque possui uma única rota acessível: o caminho para pedestres que liga a entrada do Parque ao seu interior e se estende até a parte interna do MBC, como já mencionado. Essa rota acessível possui piso regular, firme e estável, mas sem as sinalizaçóes visual e tátil que a Norma ABNT NBR 9050/2015 exige. Os demais atrativos do Parque na área externa, como a Trilha do Óleo, o Cantinho da Abelha, a Pista de Caminhada e o Parque Infantil não estão interligados por uma rota acessível e o piso até esses atrativos é de bloquetes e terra batida.

Ainda na parte externa há uma escada que liga a área de lazer ao MBC que possui uma largura de 1,50 $\mathrm{m}$ e apenas um corrimão na altura de $0,72 \mathrm{~m}$, próximo à vegetação alta. A largura da escada está dentro das normas exigidas (mínimo de $1,20 \mathrm{~m}$ ) e o corrimão está parcialmente adaptado, pois a altura que possui está dentro da Norma, mas deveria possuir uma segunda altura (0,92 $\mathrm{m}$ e $0,70 \mathrm{~m})$.

A área de circulação externa abrange o estacionamento, já descrito no tópico anterior: as vagas reservadas não estão em uma superfície plana, regular e estável, mas estão ligadas à rota acessível até o $\mathrm{MBC}$, como exigido pela Norma. Nota-se que a existência das vagas reservadas por si só não garante a acessibilidade. Carvalho (2012) encontrou irregularidades no piso das vagas reservadas para pessoas com deficiência no Parque Nacional da Serra da Capivara; e Araújo et al. (2009) observam que muitos dos espaços que estudaram possuem as adaptações básicas e mais evidentes, mas não garantem realmente a acessibilidade a diferentes públicos - algo que se assemelha ao encontrado no PNMVS.

Na perspectiva da circulação interna estão descritas as dimensões para as portas e maçanetas. No PNMVS foram analisadas a porta de entrada do MBC e a porta do banheiro acessível. Apenas a porta de entrada do $\mathrm{MBC}$ possui a largura superior ao exigido (sendo de 1,70 m), mas a largura do banheiro acessível possui apenas $0,75 \mathrm{~m}(0,05 \mathrm{~m}$ a menos que o exigido, que é $0,80 \mathrm{~m})$. A porta do banheiro possui uma maçaneta do tipo alavanca e está posicionada a uma altura de 1,10 $\mathrm{m}$ do chão, o que é compatível com as exigências da Norma ABNT NBR 9050/2015. Observa-se que muitos estudos se dedicam a identificar a existência ou não dos sanitários adaptados, mas não se certificam das medidas das portas, como é o caso do trabalho de Silva e Soares (2011) que avaliaram a acessibilidade do Parque do Sabiá, localizado em Uberlândia/MG, a partir da presença ou ausência das estruturas, sem a aferição das medidas.

d) Sanitários, banheiros e vestiários: os três sanitários do PNMVS ficam situados na parte interior do MBC (um feminino, um masculino e um sanitário unissex para pessoas com deficiência).

O sanitário adaptado possui entrada independente, mas sua porta não é identificada e no dia da pesquisa estava sem luz. A área de circulação do sanitário segue a Norma, com 2,00 m por 1,47 m, o que permite a realização das manobras de transferência. O lavatório está a uma altura total de $0,82 \mathrm{~m}$ do piso acabado, ultrapassando apenas $0,02 \mathrm{~m}$ do exigido na Norma e possui a uma altura livre na parte inferior de 0,64 m, abaixo do recomendado. Não há barras de apoio junto ao lavatório conforme é previsto na Norma ABNT NBR 9050/2015. Com relação aos demais itens analisados, tanto a bacia sanitária quanto o acionamento da descarga estão dentro dos padrões.

Com relação aos acessórios, foi verificada a presença somente da papeleira e do cabide e, considerando as alturas dos itens em relação ao chão e as respectivas distâncias em relação à borda frontal da bacia verificouse que nenhum dos dois acessórios está posicionado de forma adequada. Como já mencionado no item anterior, muitos trabalhos, como o de Nascimento; Paz (2015) mencionam apenas a existência ou não de sanitários adaptados. Poucas pesquisas, como as de Melo et al. (2010) e Chagas (2010) realizaram a medição das estruturas internas dos sanitários das áreas estudadas - e as duas pesquisas identificaram que 
os sanitários adaptados analisados não estavam equipados de forma acessível. Todos os equipamentos e respectivas dimensões exigidas pela Norma ABNT NBR 9050/2015 são importantes para as pessoas com deficiência física, assim como o piso tátil é fundamental para direcionar os usuários com deficiência visual até o sanitário e a pia.

e) Mobiliários urbanos: são objetos existentes nas vias e nos espaços públicos que podem ser adicionados ou superpostos aos elementos de urbanização. Neste item os dois bebedouros situados na parte externa do $\mathrm{MBC}$ foram avaliados. $\mathrm{O}$ acesso a eles é prejudicado devido ao caminho estreito de apenas $0,80 \mathrm{~m}$ de largura e pela vegetação que avança ali. Um bebedouro é do tipo pressão, apenas com uma altura de bica e não possui uma altura livre inferior adequada para a aproximação de pessoas com cadeira de rodas. O outro bebedouro é feito em azulejo, com uma torneira para saída da água e também não possui uma área de aproximação para cadeirantes e nenhum indicativo visual ou tátil para as demais deficiências.

Problemas semelhantes foram percebidos por Queiroz (2014) no Parque do Povo, na cidade de São Paulo: foram observados bebedouros com diferentes alturas, mas sem área para aproximação. $\mathrm{O}$ autor ressalta ainda a necessidade dos mobiliários urbanos estarem posicionados foram da rota de acesso, para que as pessoas com deficiência visual não esbarrem ou caiam e sofram alguma lesão ou ferimento (QUEIROZ, 2014).

f) Mobiliário: dos itens previstos pela ABNT NBR 9050/2015 apenas as mesas da parte interna do Museu de Biodiversidade do Cerrado foram averiguadas no PNMVS. Há três mesas para uso dos visitantes na parte interna do Museu, sendo duas para leitura e pesquisa, uma com 0,96 m de altura e a outra com 0,75 m de altura, e uma que está com os computadores apoiados e possui altura de $0,75 \mathrm{~m}$ do chão e tem a dimensão necessária de espaço livre para aproximação de pessoas com cadeira de rodas. Com relação à altura das mesas, apenas a mesa com 0,96 de altura não está seguindo o padrão. As demais mesas estão dentro do recomendado.

Queiroz (2014) constatou em sua pesquisa muitas mesas colocadas em espaços abertos, feitas de concreto, com bancos do mesmo material fixados ao chão, impossibilitando a aproximação de cadeirantes. E muitas vezes essas mesas estão localizadas em superfícies totalmente gramadas, dificultando o acesso tanto para pessoas com deficiência física quanto para pessoas com deficiência visual. As adaptações necessárias no PNMVS são simples, já que estão localizadas em piso estável e possuem espaço para circulação com cadeiras móveis, que podem ser retiradas para o uso de cadeirantes. Mas o tipo de mesa pode dificultar a aproximação e o uso por pessoas com mobilidade reduzida e por deficientes visuais.

g) Equipamentos Urbanos: entre os itens mencionados nesse tópico na ABNT NBR 9050 foram analisados: Locais de esporte, lazer e turismo; Bibliotecas e centros de leituras.

No item Locais de esporte, lazer e turismo encontra-se o subitem Parques, praças e locais turísticos que foi analisado. Segundo a NBR 9050, toda vez que esses locais possuírem pavimentação, mobiliário ou equipamentos edificados, devem ser acessíveis, aspecto já mencionado. Além disso, o subitem aborda a necessidade do máximo grau de acessibilidade com a menor intervenção do meio ambiente em locais em que as características ambientais devem ser preservadas. Nesse quesito, o PNMVS apresenta pouquíssima intervenção do meio ambiente, uma vez que é uma área preservada, além de ainda utilizar de recursos naturais, como troncos e galhos, para elaboração das placas, escadas e brinquedos.

No item Bibliotecas e centros de leitura é recomendado que tenham publicações em Braille e outros recursos audiovisuais. A biblioteca "Dr. Kerr", localizada na parte interior do Museu de Biodiversidade do Cerrado, foi analisada neste quesito. Ela não possui publicações em Braille mas existem recursos audiovisuais, como computadores e tablets, contudo estes não estavam disponíveis no momento da coleta de dados e não foram avaliados mais profundamente.

Maciel et al. (2010) sugerem a elaboração de cartilhas em Braille contendo informações ecológicas do local para os visitantes com deficiência visual. Essas cartilhas podem ser elaboradas com diferentes temas e ficarem à disposição na biblioteca do PNMVS. Centros de leituras em UCs podem ser um meio de incorporar informações sobre esses espaços para seus visitantes, principalmente se a UC possuir centro de educação ambiental que recebe visitas agendadas das escolas. 


\section{CONSIDERAÇÕES FINAIS}

A garantia de acessibilidade para pessoas com diferentes deficiências deve ser um compromisso de todos, principalmente no que se refere ao planejamento e gestão de espaços e serviços públicos. Parques Naturais urbanos que também se configuram como unidades de conservação possuem uma dupla responsabilidade: de contribuir para a sustentabilidade ambiental e também proporcionar um espaço de lazer e entretenimento para a população local.

Os resultados obtidos evidenciam que o PNMVS não apresenta todas as estruturas para acessibilidade que a ABNT NBR 9050/2015 exige. As estruturas existentes, como rampas, placas, sanitário adaptado e espaço livre para deslocamento não estão com todas as dimensões recomendadas. Verifica-se também que a maioria dessas estruturas adaptadas beneficia diretamente as pessoas com deficiência física, parcialmente as pessoas com deficiência auditiva e não contempla as pessoas com deficiência visual.

Os deficientes auditivos conseguem usufruir das estruturas físicas do Parque, uma vez que possuem o sentido da visão saudável e conseguem se autoguiarem. Mas são prejudicados pela falta de alertas visuais e outras sinalizações e informações mais específicas, como placas explicativas e ilustrativas, bem como a falta de preparo dos educadores ambientais em se comunicarem em LIBRAS. Os deficientes visuais não são contemplados com as estruturas de acessibilidade do PNMVS, já que não há piso tátil direcional e de alerta, não existem placas informativas em alto relevo ou em Braille, nem dispositivos de som. Logo, esse público não consegue se locomover sozinho com autonomia e segurança.

A pesquisa realizada indica que não é possível tornar uma unidade de conservação totalmente acessível de acordo com o que a ABNT NBR 9050 exige, tendo em vista que ambientes naturais protegidos não podem ser impactados e alterados drasticamente já que a legislação permite somente o uso indireto dos recursos naturais (BRASIL, 2000b).

Portanto, as adaptações devem ser compatíveis com a legislação ambiental e com os objetivos de cada unidade. O PNMVS, que possui objetivos de conservação e preservação do Cerrado e de promoção de Educação Ambiental, além de funcionar como um espaço de lazer, deve receber as melhorias possíveis de forma a melhorar o usufruto da área por visitantes, aumentando a autonomia e a segurança dos diferentes usuários.

\section{REFERENCIAS}

ARAÚJO, C. D.; CÂNDIDO, D. R. C.; LEITE, M. F. Espaços públicos de lazer: um olhar sobre a acessibilidade para portadores de necessidades especiais. Licere, Belo Horizonte, v. 12, n. 4, p. 1 - 43, 2009.

ASSOCIAÇÃO BRASILEIRA DE NORMAS TÉCNICAS. NBR 9050: Acessibilidade a edificações, mobiliário, espaços e equipamentos urbanos. Rio de Janeiro, 2015.

BIZINELLI, C.; MANOSSO, F.; GIMENES-MINASSE, M. H.; DE SOUZA, S. Enoturismo e Turismo de Experiência: novas possibilidades para a inclusão de pessoas com deficiência visual - Vinícola Dezem. Turismo e Sociedade, v. 7, n. 3, p. 495-522, 2014

BORGES, J. Sustentabilidade e acessibilidade: educação ambiental, inclusão e direitos da pessoa com deficiência práticas, aproximações teóricas, caminhos e perspectivas! Brasília: OAB Conselho Federal, 2014. 212 p.

BRASIL. Constituição da República Federativa do Brasil de 1988. Disponível em: http://www.planalto.gov.br/ ccivil_03/Constituicao/Constituicao.htm Acesso em: 20 dez. 2016.

BRASIL. Decreto no 3298, de 20 de dezembro de 1999. Regulamenta a Lei no 7.853, de 24 de outubro de 1989. Disponível em: http://www.planalto.gov.br/ccivil_03/decreto/d3298.htm Acesso em: 20 dez. 2016.

BRASIL. Lei no 10098, de 19 de dezembro de 2000a. Disponível em: < http://www.planalto.gov.br/ccivil_03/leis/ L10098.htm> Acesso em: 19 dez. 2016. 
BRASIL. Lei no 9985, de 18 de julho de 2000b. Regulamenta o art. 225, $₫ 1$ 1o, incisos I, II, III e VII da Constituição Federal. Disponível em: http://www.planalto.gov.br/ccivil_03/leis/19985.htm Acesso em: 20 dez. 2016.

BRASIL. Decreto $\mathbf{n}^{\circ}$ 8166, de 5 de maio de 2000c. Disponível em: http://cm-uberlandia.jusbrasil.com.br/ legislacao/844993/decreto-8166-00?ref=topic_feed Acesso em: 20 dez. 2016.

BRASIL. Lei $\mathbf{n}^{\circ}$ 13146, de 6 de julho de 2015. Lei brasileira de inclusão da pessoa com deficiência (Estatuto da Pessoa com Deficiência). Disponível em: http://www.planalto.gov.br/ccivil_03/_Ato2015-2018/2015/Lei/ L13146.htm Acesso em: 20 nov. 2016.

\section{REFERENCIAS}

BRASÍLIA. Legislação brasileira sobre pessoa com deficiência: 7.ed. Brasília: Câmara dos Deputados, 2013.410 p.

\section{REFERENCIAS}

CARVALHO, S. Acessibilidade do turismo no Parque Nacional da Serra da Capivara - PI. Turismo em análise, v. 23, n. 2, p. $437-463,2012$.

\section{REFERENCIAS}

CHAGAS, G. Acessibilidade para pessoas portadoras de deficiência física motora nos três Parques mais antigos da cidade de Curitiba: Passeio Público, Parque Barigui, Parque São Lourenço. 2010. 67 f. Trabalho de conclusão de curso (Bacharel em Turismo), Universidade Positivo, Curitiba, 2010.

COIMBRA, F. A Educação Ambiental no Parque Municipal Victório Siquierolli: diagnóstico e perspectiva. 2005. 157 f. Dissertação (Mestrado em Ecologia e Conservação dos Recursos Naturais), Universidade Federal de Uberlândia, Uberlândia-MG, 2005.

COIMBRA, G.; CUNHA, O. A Educação ambiental não formal em Unidades de Conservação: a experiência do Parque Municipal Victório Siquierolli. In: V Encontro Nacional de Pesquisa em Educação em Ciências. 2005, Uberlândia. Anais...Uberlândia: UFU, 2005. p. 1-13.

DA SILVA, C.; LEAL, S. Acessibilidade: visita técnica a três dos melhores restaurantes de Natal, Rio Grande do Norte, Brasil. Turismo e Sociedade, v. 4, n. 2, p. 343-362, 2011.

DUARTE, D.; BORDA, G. Acessibilidade e sustentabilidade: a experiência da hotelaria de Brasília. Revista Brasileira de Pesquisa em Turismo, v. 7, n. 3, p. 365-383, 2013.

FRANZEN, L.; REIS, T. Turismo e Hospitalidade: um estudo sobre o atendimento ao turista deficiente e com mobilidade reduzida em hotéis de Santa Maria/RS, Brasil. Revista Hospitalidade, v. 10, n. 2, p. 249-274, 2013.

IBGE. Censo Demográfico 2010: Características gerais da população, religião e pessoas com deficiência. IBGE: Rio de Janeiro: 2012.

IBGE. Cidades - Uberlândia. Disponível em: https://cidades.ibge.gov.br/. Acessado em 15.jan.2017.

LINE, J.; MERGULHÃO, M. Educação ambiental e Inclusão Social: Participação de crianças com deficiência visual em atividades de educação ambiental. Revista Eletrônica de Biologia, São Paulo, v. 7, n. 2, p. 193 - 209, 2014.

MACIEL, J.; WACHHOLZ, C.; ALMINHANA, C. O.; BITAR, P. G.; MUHLE, R. Metodologias de uma educação ambiental inclusiva. Revista EGP, Porto Alegre, v. 1, p. 1 - 11, 2010

MELO, C.; ORLANDO, P. Acessibilidade no Parque do Sabiá na cidade de Uberlândia (MG). Revista Nacional de Gerenciamento de Cidades, v. 2, n. 9, p. 34 - 5-, 2014.

MELO, F.; BRANDÃO, S.; OLIVEIRA, C.; SILVA, K.; SANTIAGO, M.; DELGADO, N. Estudo da acessibilidade em ambientes de lazer na cidade de Natal/RN. Licere, Belo Horizonte, v. 13, n. 2, p. 1 - 19, 2010. 
MORIWAKI, E. M. Acessibilidade para pessoa com deficiência visual em Unidades de Conservação: estudo de caso do Parque Estadual do Jaraguá. 2011.46 f. Trabalho de Conclusão de Curso (Bacharelado em Turismo), Universidade Federal de São Carlos, 2011.

NASCIMENTO, J.; PAZ, R. Avaliação da Floresta Nacional de Brasília para o atendimento de pessoas com deficiência e/ou mobilidade reduzida. Revista Brasileira de Gestão Ambiental e Sustentabilidade, v. 2, n. 2, p. 3 - 23, 2015.

\section{REFERENCIAS}

OBSERVATÓRIO DO TURISMO DE MINAS GERAIS. Indicadores. Disponível em: https:// www.observatorioturismo.mg.gov.br/indicadores Recuperado em: 15.jan.2017.

\section{REFERENCIAS}

PEREIRA, M. Turismo e inclusão social: uma avaliação acerca da acessibilidade aos portadores de necessidades físicas e visuais nos equipamentos turísticos de Belém, PA. Caderno Virtual de Turismo, v. 11, n. 2, p. 253-266, 2011.

QUEIROZ, V. Acessibilidade para pessoa com deficiência visual: uma análise de Parques Urbanos. 2014. 435 f. Dissertação (Mestrado em Arquitetura e Urbanismo), Faculdade de Arquitetura e Urbanismo, Universidade de São Paulo, São Paulo, 2014.

\section{REFERENCIAS}

SILVA, E. A acessibilidade para pessoas com deficiência física no Parque do Sabiá e no Parque Victório Siquieroli na cidade de Uberlândia-MG. 2010. 75 f. Trabalho de conclusão de curso (Graduação em Geografia), Universidade Federal de Uberlândia, Uberlândia, 2010.

\section{REFERENCIAS}

SILVA, V.; TOSTA, Q.; OTTO, H.; BELLICANTA, J.; LINS, A.; SAMPAIO, T. Parque Itanhangá e acessibilidade às pessoas com deficiência física e visual. Licere, v. 16, n. 1, 2013.

UBERLÂNDIA. Prefeitura Municipal. Parque Municipal Victório Siquierolli. Uberlândia, 2015. Disponível em: http://www.uberlandia.mg.gov.br/2014/secretaria-pagina/51/138/secretaria.html Acesso em: 18 jan. 2016.

\section{Notas}

[1] A Associação Brasileira de Normas Técnicas é uma entidade privada, sem fins lucrativos, fundada em 1940 e se constitui no órgão responsável pela normalização técnica no Brasil.

[2] É a forma de acessibilidade sem barreiras ambientais físicas, nas residências, nos edifícios, nos espaços urbanos, nos equipamentos urbanos, nos meios de transporte individual ou coletivo.

[3] Acessibilidade sem preconceitos, estigmas, estereótipos e discriminações, em relação às pessoas em geral.

[4] Acessibilidade que se dá sem barreiras na comunicação interpessoal (face a face, língua de sinais), escrita (jornal, revista, etc., incluindo textos em braile, uso do computador portátil) e virtual (acessibilidade digital).

[5] Sem barreiras nos instrumentos, utensílios e ferramentas de estudo (escolar), de trabalho (profissional), de lazer e recreação (comunitária, turística, esportiva etc.).

[6] Sem barreiras nos métodos e técnicas de estudo (escolar), de trabalho (profissional), de ação comunitária (social, cultural, artística etc.), de educação dos filhos (familiar). 
ana Beatriz Leça de Lima, et al. Acessibilidade do Parque Natural Municipal Victório Siquierolli (...

[7] Sem barreiras - muitas vezes imperceptíveis - embutidas em políticas públicas (leis, decretos, portarias etc.), normas e regulamentos (institucionais, empresariais etc.).

[8] Parque Natural Municipal do Óleo, Parque Natural Municipal Victório Siqueirolli, Parque Municipal do Distrito Industrial, Parque Municipal Luizote de Freitas, Parque Municipal Mansour, Parque Municipal Santa Luzia, Parque do Sabiá e Parque linear Rio Uberabinha

[9] O jogo consiste em placas espalhadas pela trilha, com diferentes informações sobre uma espécie de fauna do Cerrado, o tatu; e tem como objetivo fazer com que os visitantes descubram onde esse animal possa estar escondido.

[10] Sistema de escrita tátil utilizado por pessoas cegas ou com baixa visão.

[11] Os locais onde são instaladas as colmeias de meliponíneos (abelhas sem ferrão).

\section{BY}

